\title{
Challenges in Multivalvular Heart Disease: Indian Scenario
}

\author{
Suruchi Ladha ${ }^{1}$ Poonam Malhotra Kapoor ${ }^{1}$ \\ 1 Department of Cardiac Anaesthesiology, Cardiothoracic \\ NeuroCenter, All India Institute of Medical Sciences, New Delhi, India \\ J Card Crit Care TSS 2017;1:15-20.

\begin{abstract}
Address for correspondence Suruchi Ladha, MD, Department of Cardiac Anaesthesiology, Cardiothoracic NeuroCenter, All India institute of Medical Sciences (AlIMS), Ansari Nagar, New Delhi 110029, India (e-mail: suruchi.ladha@gmail.com).
\end{abstract}

Abstract
Keywords
- multivalvular disease
- echocardiographic
challenges and Indian
scenario

Multivalvular disease (MVD) is a common scenario with various clinical challenges and limited availability of evidence-based recommendations. The pathophysiology of patients having MVD is dependent on the specific combination of valve lesions. The anesthesiologist should be aware of the echocardiographic pitfalls as many commonly used echocardiographic parameters for the assessment and quantification of valve lesions is validated only in patients with single-valve disease. It is also necessary to take into account the interaction between the different valve lesions while interpreting echocardiography. The management decisions of such patients depend on the assessment of the different valve lesions and their effect on symptoms, pulmonary hypertension, and left ventricular dysfunction. The decision to intervene on multiple valves should take into account both the surgical risk of combined procedures and the advantages of available percutaneous techniques. In this review, we discuss the common clinical scenario, pathophysiology, echocardiographic challenges, and guideline-directed management options in patients with MVD.

\section{Introduction}

In the Indian subcontinent, patients having multivalvular disease (MVD) continue to be a frequent entity whose evaluation and management are challenging. MVD is the combination of stenosis or regurgitation, or both, on two or more valves of the heart. ${ }^{1}$ There are a large number of possible combinations in patients with MVD, and this heterogeneity leads to availability of limited data. ${ }^{2,3}$ The European Society of Cardiology (ESC) guidelines in 2012 stated that there is a lack of data on mixed and multiple valvular heart disease, and this does not allow for evidencebased recommendations. ${ }^{2}$ Although each case of MVD is different, in this review we consider the general pathophysiologic principles, assess the clinical and echocardiographic challenges to the anesthesiologist in MVD, and the potential management strategies.

\section{Incidence and Etiology}

In developing countries, rheumatic heart disease (RHD) continues to be the main etiology, whereas degenerative etiologies are increasing in developed countries. ${ }^{1,4}$ In 2011, the Society of Thoracic Surgeons (STS) reported $10.9 \%$ of the patients undergoing valve surgery to have multiple-valve intervention in North America. ${ }^{5}$ In the Euro Heart Survey conducted in 2001 in 25 countries, $20.2 \%$ of the patients with native valve disease and $14.6 \%$ of the patients undergoing valvular surgery had MVD. ${ }^{6}$ In this survey, RHD was found to be the most frequent etiology (51.4\%) of MVD, followed by degenerative valve disease (40.6\%). ${ }^{6}$ The other causes of primary MVD include endocarditis, thoracic and mediastinal radiation therapy, end-stage renal disease, carcinoid heart disease, adverse effects of drugs, etc. Patients with Marfan's syndrome, Ehlers-Danlos syndrome, trisomy 18,13 , and 15 , etc., can also present with MVD. ${ }^{3}$
DOI https://doi.org/ 10.1055/s-0037-1604171.
Copyright ( 2017 Official Publication of License terms The Simulation Society (TSS), accredited by International Society of Cardiovascular Ultrasound (ISCU) 


\section{Pathophysiology}

The natural history of MVD is determined by the relative severity of each individual lesion and the chronology and the chronicity of development. In such patients, the manifestation of proximal valve disease can obscure the manifestation of distal valve lesion. ${ }^{7}$ In addition, the consequences of various combinations of diseased valves on left ventricular (LV) and right ventricular (RV) geometry and function are generally different from the remodeling because of singlevalve disease.

\section{Echocardiographic Pitfalls in Evaluation of Multivalvular Disease}

Echocardiography is one of the mainstays in the evaluation of patients with valvular heart disease. ${ }^{8}$ However, several commonly used echocardiographic parameters have been validated only in patients with single-valve disease and may not be valid in the setting of MVD. Measurements less dependent on loading conditions such as direct planimetry, the effective regurgitant orifice (ERO), vena contracta, etc., are preferred. There is a need to combine different measurements for complete evaluation as hemodynamic interactions between valve lesions can affect various measurements. The AHA/ACC (American Heart Association/American College of Cardiology) 2014 guidelines recommend that patients with mixed valve disease may require serial evaluations at intervals earlier than recommended for single-valve lesion. ${ }^{8}$

\section{Aortic Stenosis and Mitral Regurgitation}

\section{Clinical Scenario}

Unger et al reported that some degree of mitral regurgitation (MR) is found in as many as 61 to $90 \%$ of patients undergoing aortic valve replacement (AVR) for aortic stenosis (AS). ${ }^{9}$ There can be three clinically common scenarios when an anesthesiologist can encounter this situation. The etiology of MR in patients with AS is often functional rather than anatomical. First, LV adverse remodeling due to AS can result in MR. Patients with AS develop LV dilatation and systolic dysfunction as a result of $\mathrm{LV}$ afterload mismatch, concomitant cardiomyopathy, or both. In turn, there is secondary MR due to mitral annular dilatation and leaflet tethering. ${ }^{9}$ Second, elderly patients with AS can have secondary MR. The risk factors for AS have been shown to be similar to those for atherosclerosis and coronary artery disease (CAD), so patients having significant CAD can present with severe AS and secondary ischemic MR. ${ }^{10}$ Third, patients with AS can have concomitant primary MR. Severe AS in association with significant MR is, however, one of the least common combinations of valvular lesions in RHD.

\section{Pathophysiology}

In patients having AS, the severity of MR increases with time because of several mechanisms, such as increase in the LV to left atrial (LA) pressure gradient, leading to increase in the regurgitant volume for any given ERO area, LV remodeling that may promote MV deformation, etc. ${ }^{9} \mathrm{MR}$ contributes to a low-flow state in patients with AS. ${ }^{10}$ The presence of MR, whether primary or secondary, can alter the clinical presentation of patients with AS. ${ }^{9}$

\section{Echocardiographic Pitfalls}

As described in pathophysiology, the systolic transmitral pressure gradient is increased due to AS, and hence, the echocardiographic measurements of regurgitant flow and the regurgitant volume will be increased for any given mitral regurgitant orifice area. ${ }^{11}$ There will be an increased area of mitral regurgitant jet using color-flow Doppler. In patients having secondary MR, the AHA/ACC 2014 guidelines recommend that the measurement of the proximal isovelocity surface area by two-dimensional (2D) echocardiography underestimates the true ERO because of the crescentic shape of the proximal convergence. ${ }^{12}$ The presence of MR, on the contrary, will lead to low flow, low gradient across the aortic valve. ${ }^{1}$

\section{Guideline-Directed Management}

- Table 1 highlights the salient features of the management of such combinations of valve lesions. The decision making in such patients include choosing from options such as doublevalve replacement, AVR plus mitral valve repair, isolated AVR or transcatheter aortic valve implantation (TAVI) for patients deemed at the highest surgical risk. When MR is severe, double-valve surgery is generally done. However, even in this situation, some regression may occur even if the mitral valve is not operated. ${ }^{9}$ The prevalence of moderate or severe MR in patients who undergo TAVI for severe AS ranges between 19 and $30 \%{ }^{13}$ Prediction of improvement in MR after TAVI remains challenging. Limited evidence on the combined use of TAVI and MitraClip (Abbott Vascular, Santa Clara, California, United States) suggests that the combination is possible but with limited efficacy. ${ }^{14,15}$

\section{Aortic Stenosis and Mitral Stenosis}

\section{Clinical Scenario}

In the Indian subcontinent, significant stenosis at multiple valves is usually due to RHD. Patients with degenerating AS can have progressive mitral annular calcification leading to degenerating mitral valve stenosis. ${ }^{16}$ Other causes include Shone's complex, mucopolysaccharidosis, etc.

\section{Pathophysiology}

The clinical signs of upstream lesion that is mitral stenosis (MS) usually prevails. ${ }^{7}$ If atrial fibrillation develops in such a scenario, it is poorly tolerated by the patient.

\section{Echocardiographic Pitfalls}

The severity of MS is usually not affected by the presence of AS, but the gradients across the aortic valve may be reduced, resulting in low-flow, low-gradient AS and potential underestimation of AS severity. ${ }^{7} \mathrm{LV}$ abnormal relaxation resulting from AS will increase the mitral E-wave pressure half-time. The pressure half-time method used to estimate the severity of MS is unreliable in the presence of AS. Planimetry continues to be the standard method to assess mitral area, but heavy calcifications can impair its measurement also. 
Table 1 The American and European guidelines for various combinations of aortic stenosis and mitral regurgitation

\begin{tabular}{|c|c|c|}
\hline Condition & AHA/ACC guidelines (2014) & ESC guidelines (2012) \\
\hline $\begin{array}{l}\text { Severe AS and } \\
\text { severe MR }\end{array}$ & $\begin{array}{l}\text { AVR is indicated for patients with severe AS } \\
\text { (stage C or D) when undergoing other cardiac } \\
\text { surgery. (COR I, LOE B) } \\
\text { Concomitant MV repair or replacement is indicated } \\
\text { in patients with chronic severe primary MR } \\
\text { undergoing cardiac surgery for other indications } \\
\text { (COR I, LOE B) } \\
\text { MV surgery is reasonable for patients with chronic } \\
\text { severe secondary MR (stages C and D) who are } \\
\text { undergoing AVR (COR Ila, LOE C) }\end{array}$ & $\begin{array}{l}\text { AVR is indicated in patients with severe AS } \\
\text { undergoing surgery on another valve (COR I, LOE C) } \\
\text { It is recommended that severe chronic functional } \\
\text { MR should be corrected at the time of bypass } \\
\text { surgery (COR I, LOE C) } \\
\text { In secondary MR, because of their prognostic } \\
\text { value, lower thresholds of severity, using } \\
\text { quantitative methods, have been proposed } \\
\text { ( } 20 \mathrm{~mm}^{2} \text { for EROA and } 30 \mathrm{~mL} \text { for regurgitant } \\
\text { volume) }\end{array}$ \\
\hline $\begin{array}{l}\text { Severe AS and } \\
\text { moderate MR }\end{array}$ & $\begin{array}{l}\text { Concomitant MV repair is reasonable in patients } \\
\text { with chronic moderate primary MR (stage B) } \\
\text { undergoing cardiac surgery for other indications } \\
\text { (COR Ila, LOE C) } \\
\text { MV repair may be considered for patients with } \\
\text { chronic moderate secondary MR (stage B) who are } \\
\text { undergoing other cardiac surgery (COR IIb, LOE C) }\end{array}$ & - \\
\hline $\begin{array}{l}\text { Severe MR and } \\
\text { moderate AS }\end{array}$ & $\begin{array}{l}\text { AVR is reasonable for patients with moderate AS } \\
\text { (stage B) (aortic velocity } 3.0-3.9 \mathrm{~m} / \mathrm{s} \text { ) who are } \\
\text { undergoing other cardiac surgery (COR Ila, LOE C) }\end{array}$ & $\begin{array}{l}\text { AVR should be considered in patients with } \\
\text { moderate AS undergoing surgery on another valve } \\
\text { (class lla, LOE C) }\end{array}$ \\
\hline
\end{tabular}

Abbreviations: AHA/ACC, American Heart Association/American College of Cardiology; AS, aortic stenosis; AVR, aortic valve replacement; COR, class of recommendation; EROA, effective regurgitant orifice area; ESC, European Society of Cardiology; LOE, level of evidence; MR, mitral regurgitation; MV, mitral valve.

\section{Guideline-Directed Management}

The salient features of management in such scenario is described in - Table 2. The AHA/ACC guidelines mainly refer to rheumatic mitral valve disease, and the approach to degenerative mitral valve disease may differ. ${ }^{8}$ In patients with severe AS undergoing TAVI, the concomitant MS is generally of degenerative etiology, and usually, there is no commissural fusion, and is therefore not suitable for percutaneous mitral commissurotomy. ${ }^{17}$

\section{Aortic Regurgitation and Mitral Stenosis}

\section{Clinical Scenario}

Combined aortic regurgitation (AR) and MS in the adult age group usually reflect the natural progression of valve lesions following rheumatic fever in the Indian scenario. ${ }^{18}$

\section{Pathophysiology}

In isolated MS, LV preload and diastolic pressure are reduced as a function of the severity of inflow obstruction. However, because of AR, the diastolic pressure may rise depending on the compliance. The combination of aortic regurgitation and MS results in opposite loading conditions on the LV. As the cardiac output falls with progressive degrees of MS, transaortic valve flows will decline, masking the potential severity of the aortic valve lesion, and hence, the clinical signs such as increased pulse pressure might not be observed.

\section{Echocardiographic Pitfall}

AR shortens directly measured pressure half-time proportional to the regurgitant fraction, but an increase in left ventricular compliance could offset this effect. This shortening of pressure half-time leads to mitral valve area over- estimation, ${ }^{19,20}$ Mitral valve area should not be measured from continuity equation method in the presence of AR, because the transmitral flow differs from the transaortic flow. ${ }^{20}$

\section{Guideline-Directed Management}

The guideline for managing this combination is mentioned in - Table 3.

\section{Aortic Regurgitation and Mitral Regurgitation}

\section{Clinical Scenario}

Significant regurgitation at multiple valves is usually nonrheumatic; however, in the Indian subcontinent patients with RHD can also have similar presentation. Patients with Marfan's syndrome may have both AR from aortic root dilatation and MR due to mitral valve prolapse. Myxomatous degeneration causing prolapse of multiple valves (mitral, aortic) can also occur in the absence of an identifiable connective tissue disorder. ${ }^{20}$ This condition can also be caused by primary AR and concomitant functional MR due to left ventricular enlargement, but lesions can also be primary in both valves, as in endocarditis, carcinoid disease, etc. The prevalence of secondary MR in patients with AR varies from 6 to $45 \%{ }^{21}$

\section{Pathophysiology}

This condition, characterized by severe volume overload caused by the two regurgitations, is usually poorly tolerated and results in early heart failure. Symptomatic patients with this combination of valve lesions have decreased LV function than those with isolated AR or MR, resulting in postoperative LV dysfunction. 
Table 2 The American and European guidelines for various combinations of mitral and aortic stenosis

\begin{tabular}{|l|l|l|}
\hline Combination & AHA/ACC guidelines (2014) & ESC guidelines (2012) \\
\hline $\begin{array}{l}\text { Severe MS and } \\
\text { severe AS }\end{array}$ & $\begin{array}{l}\text { Concomitant MV surgery is indicated for patients } \\
\text { with severe MS (MVA }<1.5 \mathrm{~cm}^{2} \text {, stage C or D) } \\
\text { undergoing other cardiac surgery. (COR I, LOE C) } \\
\begin{array}{l}\text { AVR is indicated for patients with severe AS } \\
\text { (stage C or D) when undergoing other cardiac } \\
\text { surgery for other conditions when there is } \\
\text { decreased systolic opening of a calcified aortic } \\
\text { valve and an aortic velocity of } \geq 4 \mathrm{~m} / \mathrm{s} \text { or mean } \\
\text { gradient } \geq 40 \text { mm Hg. (COR I, LOE B) }\end{array}\end{array}$ & $\begin{array}{l}\text { Severe concomitant aortic valve disease is a con- } \\
\text { traindication for PTMC } \\
\text { In patients with severe MS combined with severe } \\
\text { aortic valve disease, surgery is preferable } \\
\text { AVR is indicated in patients with severe AS } \\
\text { undergoing surgery of another valve (COR I, LOE C) }\end{array}$ \\
\hline $\begin{array}{l}\text { Severe MS and } \\
\text { moderate AS }\end{array}$ & $\begin{array}{l}\text { AVR is reasonable for patients with moderate AS } \\
\text { (stage B) (aortic velocity 3.0-3.9 m/s) who are } \\
\text { undergoing other cardiac surgery (COR Ila, LOE C) }\end{array}$ & $\begin{array}{l}\text { In patients with severe MS and moderate aortic } \\
\text { valve disease, PMC can be performed as a means of } \\
\text { postponing the surgical treatment of both valves }\end{array}$ \\
\hline $\begin{array}{l}\text { Severe AS and } \\
\text { moderate MS }\end{array}$ & $\begin{array}{l}\text { Concomitant mitral valve surgery may be } \\
\text { considered for patients with moderate MS (MVA } \\
1.6-2.0 \mathrm{~cm}{ }^{2} \text { ) undergoing other cardiac surgery } \\
\text { (COR IIb, LOE C) }\end{array}$ & \\
\hline
\end{tabular}

Abbreviations: AHA/ACC, American Heart Association/American College of Cardiology; AS, aortic stenosis; AVR, aortic valve replacement; COR, class of recommendation; ESC, European Society of Cardiology; LOE, level of evidence; MV, mitral valve. MVA, mitral valve area; PMC, percutaneous mitral commissurotomy; PMTC, percutaneous transvenous mitral commissurotomy.

\section{Echocardiographic Pitfall}

The use of Doppler volumetric method is not validated. ${ }^{1}$

\section{Guideline-Directed Management}

In treating combined $\mathrm{AR}$ and $\mathrm{MR}$, the incomplete reversibility of left ventricular dilatation due to AR should be kept in mind. If indications for AVR are fulfilled, concomitant mitral valve repair should be considered. ESC 2012 guideline states that If AR requiring surgery is associated with severe MR, both should be operated on. ${ }^{2}$

\section{Mixed Aortic Valve Disease}

There is paucity of data about the natural history of combined AS and AR, making evidence-based recommendations regard- ing AVR challenging. ${ }^{22}$ In clinical practice, the management of patients with combined aortic valve disease usually follows the recommendations of the predominant lesion. ${ }^{2}$ The current indications for surgery have been defined for single-valve disease and are "extrapolated" to patients with mixed-valve disease. The peak aortic velocity is a reliable prognostic indicator for isolated $\mathrm{AS}^{23}$ but in combined disease, it is likely to overestimate the severity of stenosis because of increased stroke volume. This increased velocity will also lead to increased LV aortic Doppler-derived pressure gradient to values higher than expected for the true systolic valve orifice size as measured by planimetry. The pressure half-time used for evaluating AR may be prolonged when left ventricular hypertrophy with impaired relaxation is present due to AS. Thus the

Table 3 The American and European guidelines for various combinations of mitral stenosis and aortic regurgitation

\begin{tabular}{|l|l|l|}
\hline Combination & AHA/ACC guidelines (2014) & ESC guidelines (2012) \\
\hline $\begin{array}{l}\text { Severe AR and } \\
\text { severe MS }\end{array}$ & $\begin{array}{l}\text { AVR is indicated for patients with severe aortic } \\
\text { regurgitation (stage C or D) undergoing cardiac } \\
\text { surgery for other indications (COR I, LOE C) }\end{array}$ & $\begin{array}{l}\text { Surgery is indicated in patients with severe aortic } \\
\text { regurgitation undergoing surgery on another valve } \\
\text { (COR I, LOE C) }\end{array}$ \\
\hline $\begin{array}{l}\text { Severe MS and } \\
\text { moderate AR }\end{array}$ & $\begin{array}{l}\text { AVR is reasonable in patients with moderate aortic } \\
\text { regurgitation undergoing other cardiac surgery } \\
\text { (COR Ila, LOE C) } \\
\text { MV surgery is reasonable for severely symptomatic } \\
\text { patients (NYHA class III/IV) with severe MS (MVA } \\
1.5 \mathrm{~cm}^{2}, \text { stage D), provided there are other op- } \\
\text { erative indications (aortic valve disease) (COR Ila, } \\
\text { LOE C) }\end{array}$ & $\begin{array}{l}\text { In patients with moderate AR, who undergo MV } \\
\text { surgery, the decision to treat the aortic valve } \\
\text { should be based on the etiology of the AR, age, } \\
\text { worsening of LV function, and the possibility of } \\
\text { valve repair. }\end{array}$ \\
\hline $\begin{array}{l}\text { Severe AR and } \\
\text { moderate MS }\end{array}$ & $\begin{array}{l}\text { Concomitant MV surgery may be considered for } \\
\text { patients with moderate MS (MVA 1.6-2.0 cm }{ }^{2} \text { ) } \\
\text { undergoing other cardiac surgery (COR IIb, LOE C) }\end{array}$ & \\
\hline
\end{tabular}

Abbreviations: AHA/ACC, American Heart Association/American College of Cardiology; AR, aortic regurgitation; AVR, aortic valve replacement; COR, class of recommendation; ESC, European Society of Cardiology; LOE, level of evidence; LV, left ventricular; MV, mitral valve. MVA, mitral valve area; NYHA, New York Heart Association. 
Table 4 The American and European guidelines for treatment of TR

\begin{tabular}{|c|c|c|c|c|}
\hline Condition & AHA/ACC guidelines (2014) & & ESC guid & (2012) \\
\hline $\begin{array}{l}\text { Primary TR } \\
\text { Severe TR undergoing left-sided surgery }\end{array}$ & COR & LOE & COR & LOE \\
\hline Moderate TR undergoing left-sided surgery & Not specified & $\mathrm{C}$ & Illa & $\begin{array}{l}\mathrm{C} \\
\mathrm{C}\end{array}$ \\
\hline $\begin{array}{l}\text { Secondary TR } \\
\text { Severe TR undergoing left-sided surgery }\end{array}$ & I & C & I & C \\
\hline $\begin{array}{l}\text { Mild or moderate TR with dilated annulus } \\
\left(\geq 40 \mathrm{~mm} \text { or. } 21 \mathrm{~mm} / \mathrm{m}^{2} \text { ) }\right. \\
\text { undergoing left-sided surgery }\end{array}$ & $\begin{array}{l}\text { Ila (with RV dilatation or prior } \\
\text { right-sided heart failure) }\end{array}$ & B & Ila & C \\
\hline $\begin{array}{l}\text { Moderate TR and PH undergoing } \\
\text { left-sided surgery }\end{array}$ & $\mathrm{IIb}$ & C & $\begin{array}{l}\text { Not } \\
\text { specified }\end{array}$ & \\
\hline
\end{tabular}

Abbreviations: AHA/ACC, American Heart Association/American College of Cardiology; COR, class of recommendation; ESC, European Society of Cardiology; LOE, level of evidence; PH, pulmonary hypertension; RV, right ventricular; TR, tricuspid regurgitation.

quantification of the severity of combined aortic valve disease is complex as the measures of severity are affected by the coexisting lesion. ${ }^{3}$ Aortic valve area may not provide required information as it reflects the severity of AS only, and not accounting for the severity of AR. ${ }^{23}$

\section{Mixed Mitral Valve Disease}

Similar to the aforementioned mixed aortic valve disease, in mixed mitral valve disease the peak mitral valve E-wave velocity may be increased. In the setting of severe MR because of enhanced early-diastolic flow, the peak mitral valve E-wave velocity may not accurately reflect the contribution to LA hypertension from any associated MS. When AR or MR is the dominant lesion in patients with mixed aortic or mitral valve disease, respectively, the LV is dilated. When AS or MS predominates, LV chamber size will be normal or small. Also, the presence of moderate or severe MR in patients with rheumatic MS is a contraindication to percutaneous mitral balloon valvotomy (PMBV). ${ }^{2}$

\section{Tricuspid Regurgitation and Left-Sided Valve Disease}

Primary (or organic) TR is caused by congenital or acquired abnormalities of the tricuspid valve (TV). Secondary (or functional) TR occurs due to deformation of the TV apparatus. The majority of TR is secondary to conditions that cause RV and/or right atrial dilatation, including left-sided heart disease and chronic atrial fibrillation. Approximately 20 to 30\% of patients undergoing cardiac surgery for left-sided valvular disease present with significant TR. Both ESC 2012 and ACC/ AHA 2014 guidelines favor a more proactive approach to TR correction and highlight the shifting consensus toward a liberal approach to surgical correction ( - Table 4). ${ }^{2,8}$ There is a common consensus that severe TR should be treated in patients undergoing left-sided cardiac surgery. The guidelines strongly encourage the surgical correction of less than severe functional TR if the tricuspid annulus dilation is $>40 \mathrm{~mm}$ on TTE $\left(>21 \mathrm{~mm} / \mathrm{m}^{2}\right)$ or $>70 \mathrm{~mm}$ on direct intraoperative measurement in patients undergoing leftsided valve surgery. ${ }^{8}$

\section{Conclusion}

The thorough understanding of the pathophysiology and the echocardiographic challenges will help in better management of the various situations arising from different combinations of the valve lesions in patients with MVD. It is important to understand both the diagnostic and therapeutic challenges in such clinical scenarios. The global consequences of all lesions should be considered before any decision making. The perioperative risk and benefits of double-valve surgical intervention should be considered on a case-by-case basis. The use of percutaneous intervention in patients with MVD is in its infancy, but the future development of transcatheter techniques will offer the possibility of staged procedures in high-risk patients.

\section{References}

1 Unger P, Clavel MA, Lindman BR, Mathieu P, Pibarot P. Pathophysiology and management of multivalvular disease. Nat Rev Cardiol 2016;13(07):429-440

2 Vahanian A, Alfieri O, Andreotti F, et al; Joint Task Force on the Management of Valvular Heart Disease of the European Society of Cardiology (ESC); European Association for Cardio-Thoracic Surgery (EACTS). Guidelines on the management of valvular heart disease (version 2012). Eur Heart J 2012;33(19):2451-2496

3 Unger P, Rosenhek R, Dedobbeleer C, Berrebi A, Lancellotti P. Management of multiple valve disease. Heart 2011;97(04): 272-277

4 Goldbarg SH, Elmariah S, Miller MA, Fuster V. Insights into degenerative aortic valve disease. J Am Coll Cardiol 2007; 50(13):1205-1213

5 Lee R, Li S, Rankin JS, et al; Society of Thoracic Surgeons Adult Cardiac Surgical Database. Fifteen-year outcome trends for valve surgery in North America. Ann Thorac Surg 2011;91(03):677-684 , discussion 684

6 Iung B, Baron G, Butchart EG, et al. A prospective survey of patients with valvular heart disease in Europe: The Euro Heart Survey on Valvular Heart Disease. Eur Heart J 2003;24(13):1231-1243

7 Unger P, Lancellotti P, de Cannière D. The clinical challenge of concomitant aortic and mitral valve stenosis. Acta Cardiol 2016; 71(01):3-6 
8 Nishimura RA, Otto CM, Bonow RO, et al; American College of Cardiology/American Heart Association Task Force on Practice Guidelines. 2014 AHA/ACC guideline for the management of patients with valvular heart disease: executive summary: a report of the American College of Cardiology/American Heart Association Task Force on Practice Guidelines. J Am Coll Cardiol 2014; 63(22):2438-2488

9 Unger P, Dedobbeleer C, Van Camp G, Plein D, Cosyns B, Lancellotti P. Mitral regurgitation in patients with aortic stenosis undergoing valve replacement. Heart 2010;96(01):9-14

10 Unger P, Plein D, Van Camp G, et al. Effects of valve replacement for aortic stenosis on mitral regurgitation. Am J Cardiol 2008;102 (10):1378-1382

11 Paradis JM, Fried J, Nazif T, et al. Aortic stenosis and coronary artery disease: what do we know? What don't we know? A comprehensive review of the literature with proposed treatment algorithms. Eur Heart J 2014;35(31):2069-2082

12 Lancellotti P, Tribouilloy C, Hagendorff A, et al; Scientific Document Committee of the European Association of Cardiovascular Imaging. Recommendations for the echocardiographic assessment of native valvular regurgitation: an executive summary from the European Association of Cardiovascular Imaging. Eur Heart J Cardiovasc Imaging 2013;14(07):611-644

13 Bax JJ, Delgado V, Bapat V, et al. Open issues in transcatheter aortic valve implantation. Part 1: patient selection and Treatment strategy for transcatheter aortic valve implantation. Eur Heart J 2014;35:262738

14 Rudolph V, Schirmer J, Franzen O, et al. Bivalvular transcatheter treatment of high surgical risk patients with coexisting severe aortic stenosis and significant mitral regurgitation. Int J Cardiol 2013;167:71620
15 Kische S, D’Ancona G, Paranskaya L, et al. Staged total percutaneous treatment of aortic valve pathology and mitral regurgitation: institutional experience. Catheter Cardiovasc Interv 2013; 82(04):E552-E563

16 Tyagi G, Dang P, Pasca I, Patel R, Pai RG. Progression of degenerative mitral stenosis: insights from a cohort of 254 patients. J Heart Valve Dis 2014;23(06):707-712

17 Himbert D, Bouleti C, Iung B, et al. Transcatheter valve replacement in patients with severe mitral valve disease and annular calcification. J Am Coll Cardiol 2014;64(23):2557-2558

18 Manjunath CN, Srinivas P, Ravindranath KS, Dhanalakshmi C. Incidence and patterns of valvular heart disease in a tertiary care high-volume cardiac center: a single center experience. Indian Heart J 2014;66(03):320-326

19 Flachskampf FA, Weyman AE, Gillam L, Liu CM, Abascal VM Thomas JD. Aortic regurgitation shortens Doppler pressure half-time in mitral stenosis: clinical evidence, in vitro simulation and theoretic analysis. J Am Coll Cardiol 1990;16(02): 396-404

20 van Karnebeek CD, Naeff MSJ, Mulder BJM, Hennekam RCM, Offringa M. Natural history of cardiovascular manifestations in Marfan syndrome. Arch Dis Child 2001;84(02):129-137

21 Regeer MV, Al Amri I, Versteegh MI, Bax JJ, Marsan NA, Delgado V. Mitral valve geometry changes in patients with aortic regurgitation. J Am Soc Echocardiogr 2015;28(04):455-462

22 Egbe AC, Poterucha JT, Warnes CA. Mixed aortic valve disease: midterm outcome and predictors of adverse events. Eur Heart J 2016;37(34):2671-2678

23 Rosenhek R, Zilberszac R, Schemper M, et al. Natural history of very severe aortic stenosis. Circulation 2010;121(01): $151-156$ 